\section{Advances in Clinical Chemistry}

Vol. 5. Edited by Harry Sobotka and C. P. Stewart. Pp. xiv +329 . (Now York: Academic Press; London: Academic Press, Inc. (London), Ltd., 1962.) $86 s$.

UMBER 5 is one of the best volumes which have so far appeared in this useful series. As usual the contents cover a wide range of totally unrelated subjects all of which are of present-day importance and the treatment varies from general theoretical discussion to søvere practical detail.

The article in Volume 4 on mellituria has been followed up in Volume 5 by an exhaustive account of galactosæmia by I. I. Woolf covering not only the clinical features and the biochemical and genetical aspects but also the details of the laboratory diagnosis and the treatment. This is an excellent example of a molecular disease which lends itself to rational treatment now that the biochemical basis is properly understood. It is proposed to deal with other examples of molocular disease in future volumes.

Another clinical entity which is lending itself to rational therapy now that the nature of the causative factors is becoming less obscure is the malabsorption syndrome which is discussed by A. C. Frazer with special reference to the recont work on the mechanism of the effects of wheat gluten.

Two chapters are devoted to less familiar topics. Haptoglobins are dealt with by C. B. Laurell and C. Grönvall, and peptiduria, a much less well-recognized condition than aminoaciduria, by the late B. Skarzynski and M. Sarnecka-Keller.

The final two chapters are severely practical. H. Baker and H. Sobotka give full experimental details for the microbiological assay of the vitamins of the B group in biological materials, while Bruns and Werners describe the methods for estimating several enzymes, glucose-6. phosphate dehydrogenase, 6-phosphogluconate dehydrogenase, glutathione reductase, methæmoglobin reductase and sorbitol dehydrogenase. Although the treatment is exhaustive, not all clinical biochemists will find the experimental details completely adequate at the bench.

The oditors have chosen well for this volume. It is an essential tool in every clinical chemistry laboratory.

J. N. Davidoson

\section{Semiconductor Reliability}

Edited by John E. Shwop and Harold J. Sullivan. Pp. ix + 309. (Elizabeth, N.J.: Engineering Publishers, 1961. Distributed by Reinhold Publishing Corporation, New York; and Chapman and Hall, Ltd., London.) 68s. net.

7 HIS book is based on the 1961 conference on reliability of semiconductor devices and contains twentyfive papers.

We are now reaching a state when the reliability of the newer types of semiconductor devices promises to be so good that it will no longer be a major consideration to the equipment designer. The limiting factors in the reliability of equipment are much more likely to be the interconnexion systems, and methods of incorporating the semiconductor devices into the circuits.

This high reliability of semiconductor devices also brings with it difficulties in measuring failure rates since these are so low. In fact it is almost inevitable that reliability information obtained by ordinary methods of life test will relate to out-of-date devices. This tendency is evident in this book since it is generally agreed that planar semiconductor devices are likely to be the most reliable, and only one paper of the twenty-five deals specifically with planar transistors. However, some of the contributions in the book are important in that they point the way to new methods of life-testing components which may give indications of very long life expectancy from life tests of much shorter duration carried out under overstressed conditions. The paper by D. S. Leck, for example, foreshadows the now widely accepted method of 'step-stress' testing.

An interesting speculation is whether useful information may be obtained by recording small parameter changes during step-stress testing as a barometer of production quality which will enable reliability to be improved even more.

A. A. SHEPhERD

\section{Compound Semiconductors}

Edited by Robert K. Willardson and Harvey L. Goering. Vol. 1: Preparation of III-V Compounds. Pp. xxii +553. (New York: Reinhold Publishing Corporation; London: Chapman and Hall, Ltd., 1962.) 25 dollars; $200 \mathrm{~s}$.

THIS book is a compilation of the work of many authors of original papers on the preparation and properties of III/V compounds. Although the book is largely based on original papers, each chapter has been specially written by the author concerned, and a considerable amount of hitherto unpublished material is included.

Its 53 chapters are grouped into ten sections, dealing with crystal structure, purification of the elements, impurity detection, compound preparation, single crystal growth, thin films, diffusion, segregation, surfaces, and thermodynamic properties of the compounds.

The authors of the book were selected on the basis of a bibliography of more than 1,000 papers on III/V compounds (which is included), and it is obvious that this method of selection has produced one of the most comprehensive and well-written works to date on this subject.

In addition to a thorough theoretical study of the III/V compounds, the book places considerable emphasis on the technology of purifying the component elements and preparation of the compounds in both polycrystalline and single crystal form.

It is extremely well produced by the Reinhold Publishing Corporation, and can be recommended as a necessity for any workers in the field of III/V compounds.

\section{A. A. Shepherd}

Proceedings of the International Conference on the Physics of Semiconductors held at Exeter, July 1962 Edited by A. C. Stickland. Pp. xi +909 . (London: The Institute of Physics and The Physical Society, 1962.) $210 s$.

$T^{T}$ is a measure of the rate at which semiconductor 1 problems are being worked out that this conference attracted over 130 papers suitable for publication.

The conference, which is the third in the series, the previous ones having been held at Rochester in 1958 and Prague in 1960, has undoubtedly contributed much towards the further understanding of physical phenomena in semiconductors. The papers are divided into sections dealing with transport, disordered semiconductors. effective mass determination, optical properties, lattice vibrations, band theory, magnetic properties, materials, surface effects, and recombination.

It is probably true to say that the sections on transport and optical properties contain much of the work which is providing basic information on electronic states in solids. Although many of the papers are concerned with the properties of germanium and silicon, the range of interest has now been widened; much of the material presented is concerned with what might be described as "second order" properties of metals.

It seems that the diversification of work which is occurring as solid-state physics enters this new phase will lead to a larger number of small, specialized groups working in the various parts of the subject. One fears that as time goes on, unfortunately, such groups will have less and less common ground.

The book has been excellently and promptly produced. A. A. Shepherd 